\title{
Résultats de la votation générale de la coopérative FMH Services
}

\section{Beat Bumbachera, Beat Bär ${ }^{b}$}

${ }^{a}$ Dr méd., MLaw, président du conseil d'administration de FMH Services société coopérative; ${ }^{b}$ Directeur de FMH Services société coopérative

\section{Chers Sociétaires,}

Par le rapport de gestion, nous vous avons informés en mai 2020 des activités opérationnelles et nous avons soumis à votre approbation le rapport de gestion 2019, l'affectation du résultat ainsi que la décharge au conseil d'administration de FMH Services.

Nous nous réjouissons de vous annoncer les résultats de la votation générale et nous vous remercions de votre participation nombreuse et de votre intérêt.

Veuillez agréer, chers Sociétaires, nos salutations les meilleures.

FMH Services société coopérative

\section{Votation générale 2020}

\section{Remise des bulletins de vote}

Du 15 mai au 30 juin 2020 par écrit auprès de la commune d'Oberkirch

\section{Dépouillement}

M. J.R. Rogger, commune d'Oberkirch

\section{Résultats}

\subsection{Proposition $\mathbf{n}^{\circ} 1$}

Acceptez-vous le rapport de gestion 2019 de FMH Services?

Bulletins de vote reçus 5772

Bulletins invalides (sans signature) 50

Bulletins vides ou pas de bulletin $\quad 75$

Bulletins valables 5647

Oui $\quad 5584$

Non

63

La proposition $n^{\circ} 1$ est ainsi approuvée à une large majorité.

\subsection{Proposition $\mathbf{n}^{\circ} 2$}

Êtes-vous d'accord de reporter le bénéfice de CHF 489539.03 sur l'exercice suivant et de l'attribuer aux réserves générales?

\begin{tabular}{lr}
\hline Bulletins de vote reçus & 5767 \\
\hline Bulletins invalides (sans signature) & 50 \\
\hline Bulletins vides ou pas de bulletin & 59 \\
\hline Bulletins valables & 5658 \\
\hline Oui & 5523 \\
\hline Non & 135
\end{tabular}

La proposition $n^{\circ} 2$ est ainsi approuvée à une large majorité.

\subsection{Proposition $\mathbf{n}^{\circ} 3$}

Êtes-vous d'accord de donner décharge au conseil d'administration de la coopérative FMH Services pour l'année de référence 2019?

\begin{tabular}{lr}
\hline Bulletins de vote reçus & 5740 \\
\hline Bulletins invalides (sans signature) & 50 \\
\hline Bulletins vides ou pas de bulletin & 78 \\
\hline Bulletins valables & 5612 \\
\hline Oui & 5527 \\
\hline Non & 85 \\
\hline
\end{tabular}

La proposition $n^{\circ} 3$ est ainsi approuvée à une large majorité.

\subsection{Proposition $n^{\circ} 4$}

Acceptez-vous de nommer comme organe de révision pour un nouveau mandat d'un an la firme Truvag Revisions AG à Sursee?

\begin{tabular}{lr}
\hline Bulletins de vote reçus & 5751 \\
\hline Bulletins invalides (sans signature) & 51 \\
\hline Bulletins vides ou pas de bulletin & 84 \\
\hline Bulletins valables & 5616 \\
\hline Oui & 5522 \\
\hline Non & 94
\end{tabular}

La proposition $n^{\circ} 4$ est ainsi approuvée à une large majorité.

\subsection{Proposition $n^{\circ} 5$}

Acceptez-vous de nommer, pour un nouveau mandat d'un an, l'administration communale d'Oberkirch comme instance tierce neutre pour l'exécution de la votation générale?

\begin{tabular}{lr}
\hline Bulletins de vote reçus & 5760 \\
\hline Bulletins invalides (sans signature) & 50 \\
\hline Bulletins vides ou pas de bulletin & 71 \\
\hline Bulletins valables & 5639 \\
\hline Oui & 5584 \\
\hline Non & 55
\end{tabular}

La proposition $n^{\circ} 5$ est ainsi approuvée à une large majorité.

Le résultat de cette votation générale a été confirmé le 10 juillet 2020 par J.R. Rogger, c/o administration communale d'Oberkirch, comme étant correct et exhaustif. 